\title{
Functional Analysis of Genes Involved in the Synthesis of Syringolin A by Pseudomonas syringae pv. syringae B301D-R
}

\author{
Hans Amrein, Stefan Makart, José Granado, Roshani Shakya, Jana Schneider-Pokorny, and \\ Robert Dudler
}

Institute of Plant Biology, University of Zurich, Zollikerstrasse 107, CH-8008 Zurich, Switzerland

Submitted 10 April 2003. Accepted 24 September 2003.

\begin{abstract}
Strains of the phytopathogenic bacterium Pseudomonas syringae pv. syringae secrete a family of structurally closely related peptide derivatives dubbed syringolins, of which syringolin $A$ is the major variant. The function of syringolins in the interaction of $P$. syringae pv. syringae with their host plants presently is unknown. It is hypothesized that they may constitute virulence factors. However, syringolins are determinants recognized and reacted to by nonhost plant species, and syringolin A has been shown to induce hypersensitive death of cells colonized by powdery mildew in wheat and, thus, to reprogram a compatible interaction into an incompatible one. Syringolin $A$ is an unusual derivative of a tripeptide that contains a 12-membered ring consisting of the amino acids 5-methyl-4-amino-2-hexenoic acid and 3,4-dehydrolysine, two nonproteinogenic amino acids. Here we report the cloning, sequencing, and analysis of genes involved in the biosynthesis of syringolin $A$. The genes encode proteins consisting of modules typical for nonribosomal peptide synthetases and type I polyketide synthetases, as well as proteins likely involved in the transcriptional regulation of syringolin $A$ biosynthesis and in syringolin A export. The structure and arrangement of the modules lead to the formulation of a model explaining the synthesis of the tripeptide, including the formation of the two nonproteinogenic amino acids in the ring structure of syringolin A.
\end{abstract}

Additional keywords: cepafungin, glidobactin.

Syringolins constitute a family of structurally related cyclic peptides secreted by many strains of the phytopathogenic bacterium Pseudomonas syringae pv. syringae under certain conditions (Wäspi et al. 1998, 1999). They were discovered because of their exciting ability to not only induce acquired resistance against the rice blast disease in rice plants sprayed with isolated syringolin A (Wäspi et al. 1998) but also reprogram a compatible interaction of wheat with powdery mildew into an incompatible one (i.e., to induce hypersensitive cell death of wheat cells colonized by the powdery mildew fungus Blumeria graminis f. sp. tritici) (Wäspi et al. 2001). Rice and wheat are nonhost plant species for the $P$. syringae pv. syringae strains

Corresponding author: R. Dudler; Telephone.: +41 163482 52; Fax: +41 163482 04; E-mail: rdudler@ botinst.unizh.ch

The DNA sequence reported has been deposited in the GenBank/EMBL database under the accession number AJ548826. from which syringolins were isolated. Currently, the biological function of syringolins in the interaction of $P$. syringae pv. syringae with host plants is unknown. However, because syringolin production is dependent on the gacS/gacA two-component regulatory system (Reimmann et al. 1995; Wäspi et al. 1998), which is also required for pathogenicity (Hrabak and Willis 1992, 1993), we hypothesize that syringolins may be virulence factors in interactions of the bacteria with host plant species.

We previously have determined the structure of syringolins. Syringolin A, the major variant present in conditioned media, is a compound that contains a 12 -membered ring structure consisting of the unusual nonproteinogenic amino acids 5-methyl4-amino-2-hexenoic acid and 3,4-dehydrolysine. The latter is connected by a peptide bond to a valine which, in turn, is linked to a second valine residue via an urea moiety (Fig. 1). The minor structural variants syringolin B to F differ from syringolin A by the substitution of 3,4-dehydrolysine by lysine, or of one or both valine residues by isoleucine residues, and by combinations of these substitutions (Wäspi et al. 1999). The structure and relative abundance of the syringolin variants has led to the suggestion that these peptides are synthesized by the same nonribosomal peptide synthetase (NRPS) (Wäspi et al. 1998, 1999).

Here we report the cloning and functional analysis of genes encoding the NRPS responsible for syringolin synthesis. Based on the gene structure, a model is presented which explains the synthesis of the tripeptide containing the two unusual amino acids forming the 12-membered ring structure. The model also has implications for the mechanism of biosynthesis of the antitumor antibiotics glidobactin and cepafungin, the compounds that are most similar to syringolins (Oka et al. 1988a and b; Shoji et al. 1990; Terui et al. 1990). Finally, the syringolin A mutants now available through this study will be of great value in elucidating the function of syringolins in the compatible interaction of $P$. syringae pv. syringae with its host plant species.

\section{RESULTS}

Cloning of a syringolin A peptide synthetase gene fragment.

Employing a strategy proposed for the cloning of peptide synthetase genes (Turgay and Marahiel 1994), two degenerate oligonucleotide pools (TGD1 and LGG1) were synthesized encoding amino acid sequences often conserved in many peptide synthetases. Pool TGD1 encoded the amino acid sequence TGDLAR, derived from conserved core region 4 of the amino acid activation domain, whereas pool LGG1 corresponded to the amino acid sequence GGHSLK, derived from core region 6 
(Stachelhaus and Marahiel 1995). Polymerase chain reaction (PCR) products using genomic DNA of $P$. syringae pv. syringae B301D-R (Xu and Gross 1988) as a template and oligonucleotide pools TGD1 and LGG1 as primers were separated on an agarose gel. A 500-bp band, corresponding to the size expected from the location of the relevant core regions in peptide synthetases (Turgay and Marahiel 1994), was visible in addition to fragments of different sizes. DNA fragments in the 500bp band were isolated from the gel and cloned. Of the 20 clones sequenced, 8 were fragments of the known syringomycin synthetase gene $\operatorname{syrE}$ (Guenzi et al. 1998). The other clones represented four novel sequences that showed sequence similarity to the activating domain-encoding sequences of peptide synthetase genes. To test whether any of these four sequences, designated PS1 to PS4, were part of the syringolin A synthetase gene or genes, they were subcloned into the suicide plasmid pME3087, transformed into Escherichia coli S-17 (Voisard et al. 1994), and mobilized into the wild-type strain B301D-R by mating. Single recombination events led to the chromosomal insertion of the vector with its tetracycline resistance cassette and a duplication of the cloned sequence. Thus, colonies were selected on plates containing tetracycline and chloramphenicol, which prevented growth of E. coli but not of $P$. syringae pv. syringae. Two independent tetracycline-resistant colonies of each of the four matings then were grown under syringolin A-inducing conditions and conditioned media were analyzed by high-performance liquid chromatography (HPLC) with regard to their content of syringolin A, syringomycin, and syringopeptin. The latter compounds were monitored as a positive control for the correct induction conditions, because the biosynthesis of both syringolin A and syringomycin was shown to be under the control of the gacS/gacA two-component regulatory system (Hrabak and Willis 1992; Rich et al. 1994; Wäspi et al. 1998).

These analyses revealed that PS1 appeared to be part of the syringopeptin synthetase gene or genes because the corresponding insertion mutant produced syringolin A and syringomycin, but no syringopeptin (data not shown). Indeed, PS1 turned out to be part of the recently published syringopeptin synthetase gene sypC (accession no. AF286216) (ScholzSchroeder et al. 2003). PS2 and PS4 insertion mutants still produced all three peptides (data not shown), whereas PS3 mutants produced syringomycin and syringopeptin, but no syringolin A (Fig. 2B). Thus, PS3 apparently was part of a gene involved in syringolin A production.

\section{Cloning of the genomic region around PS3.}

A lambda library was constructed from genomic DNA of $P$. syringae pv. syringae B301D-R and screened with the PS3

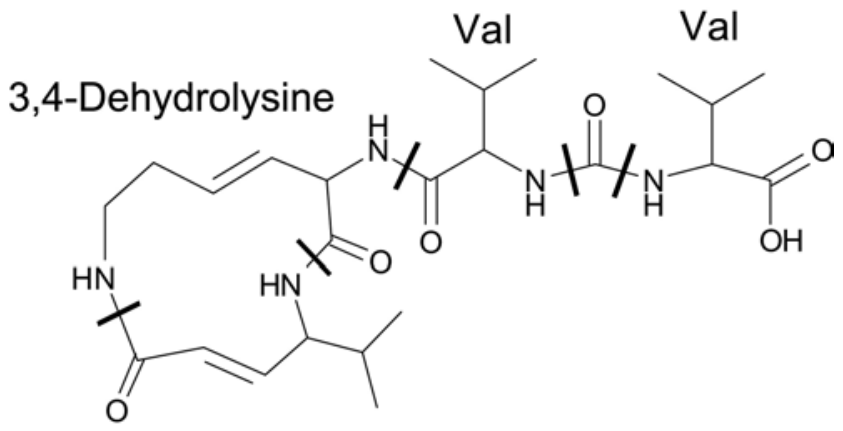

\section{5-Methyl-4-amino-2-hexenoic acid}

Fig. 1. Structure of syringolin A. The amino acid constituents of syringolin A are delimited by thick bars and labeled above and below the structure. fragment as a probe. Positive lambda clones were isolated and neighboring overlapping clones were identified using end probes. The $25-\mathrm{kb}$ genomic region depicted in Figure 3 was sequenced. Analysis of the sequence by conceptual translation of open reading frames (ORFs) and comparison to sequences in databases led to the detection of eight putative genes in the sequenced region (ORF 1 to ORF 8; Figure 3). The PS3 sequence was found to be part of ORF 4. The position of the vector insertion in the PS3 mutant was verified by PCR amplification of a DNA fragment from genomic DNA of the PS3 insertion mutant using a forward primer located outside of the PS3 PCR fragment sequence and a reverse primer (pr_3087) corresponding to a pME3087 vector sequence flanking the HindIII restriction site of the multiple cloning box. A fragment was amplified whose size and sequence were as expected if the insertion indeed occurred by homologous recombination within the PS3 sequence. We mutated all seven remaining ORFs indicated in Figure 3 by a strategy analogous to the one used for interrupting ORF 4. Thus, suitable PCR fragments corresponding to se-

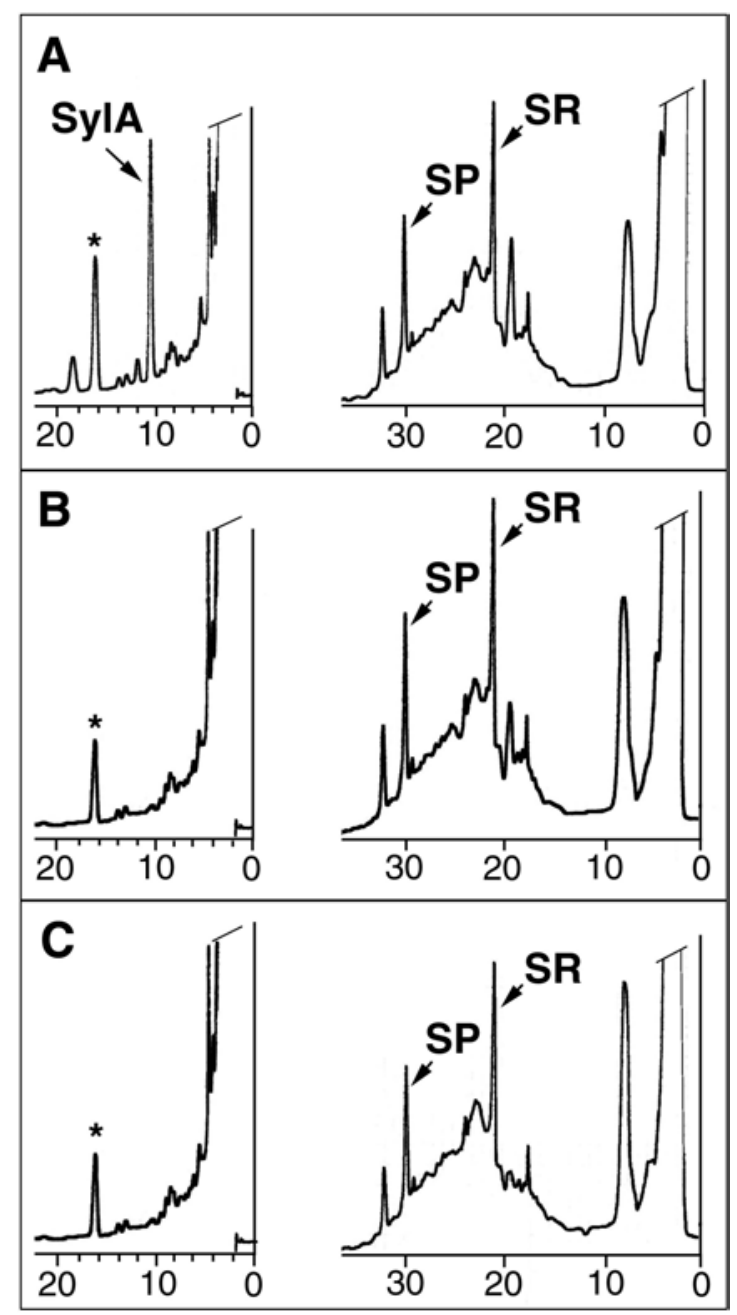

Fig. 2. Analysis of syringolin A, syringomycin, and syringopeptin content in conditioned media. The high-performance liquid chromatography (HPLC) traces show the analysis of aliquots of the same batch of conditioned media with regard to syringolin A content (left side) or syringomycin and syringopeptin content (right side) of A, wild-type bacteria and bacteria mutated in the $\mathbf{B}$, sylC and $\mathbf{C}$, sylD genes. The peaks corresponding to syringolin A (SylA), syringomycin E (SR), and syringopeptin $\mathrm{SP}_{22}-\mathrm{A}(\mathrm{SP})$ are indicated. The peak marked with an asterisk in the traces on the left side corresponds to an unknown compound unrelated to syringolins which always is visible when crude media are directly analyzed by HPLC. Numbers given on the horizontal axis of the traces indicate the elution time in minutes. 
quences within the ORFs were subcloned into pME3087 and transferred into $P$. syringae pv. syringae B301D-R. Homologous recombinants were selected and confirmed as described above. Two independent insertion mutants for all remaining ORFs were grown under syringolin A-inducing conditions and conditioned media were analyzed as to their content of syringolin A and syringomycin. All strains analyzed which carried insertions in ORF 1 (nucleotide position 681 to 3,068; encodes an putative protein of unknown function that is highly conserved in many bacterial species; data not shown), ORF 7 (reverse complement position 23,621 to 24,332), and ORF 8 (complement of nucleotide position 24,430 to $>25,621$; encodes a putative dihydroxy acid dehydratase; EC 4.2.1.9) were not detectably affected in their syringolin A production, indicating that these ORFs were not involved in the biosynthesis of the compound. These three ORFs flank the remaining set of five ORFs, all of which affect syringolin A production when mutated by insertions. In addition to ORF 4 mutants, syringolin A production also was abolished in mutants of ORF 2, ORF 3, and ORF 5 (Fig. 2C; data not shown) and reduced by approximately $80 \%$ in mutants of ORF 6 (data not shown). Syringomycin (and syringopeptin) production essentially was unaffected in all these mutants, indicating that the affected ORFs likely are involved specifically in the biosynthesis of syringolin A, and not in a more global regulatory pathway. Thus, ORF 2, ORF 3, ORF 4, ORF 5, and ORF 6 tentatively were designated $s y l A, s y l B, s y l C$, sylD, and $s y l E$, respectively (Fig. 3).

\section{sylC and sylD encode proteins}

\section{containing peptide synthetase modules.}

sylC encodes a protein of 1,328 amino acids (aa) (DNA position 5,628 to 9,611) and a predicted molecular weight of $144,759 \mathrm{Da}$ that has the typical domain structure of a peptide synthetase module (Marahiel et al. 1997) (Fig. 4). It consists of an N-terminal condensation domain (residues 43 to 343; protein families [pfam] database entry pfam00668) followed by an adenylation domain (residues 776 to 1,171; pfam00501) and a thiolation domain containing the phosphopantetheine attachment site (residues 1,262 to 1,324; pfam00550). The PS3 plasmid insertion site in the PS3 mutant was at amino acid 1,281 within the functionally essential thiolation domain.

sylD encodes a protein of 4,190 aa (DNA position 9,719 to 22,288 ) and a predicted molecular weight of $458,168 \mathrm{Da}$ with GUG as the translation initiation codon $(4,188$ aa if the next in-frame AUG codon is the initiation codon). As illustrated in
Figure 4, it contains two typical peptide synthetase modules at its N-terminus consisting of condensation (pfam00668; residues 32 to 321 and 1,100 to 1,393 ), adenylation (pfam00501; residues 509 to 923 and 1,588 to 1,980), and thiolation domains (pfam00550; residues 1,005 to 1,069 and 2,074 to 2,138 ). Surprisingly, the rest of the protein exhibits a structure similar to a typical module occurring in type I polyketide synthetases (Hopwood 1997) (Fig. 4). This module contains a putative $\beta$-ketoacyl synthetase domain, consisting of $\mathrm{N}$-terminal (pfam00109; residues 2,162 to 2,406) and C-terminal (pfam02801; residues 2,419 to 2,590) parts, followed by an acyl transferase domain (pfam 00698; residues 2,684 to 2,964); an acyl carrier protein domain (ACP), including the phosphopantetheine attachment site (pfam00550; residues 3,828 to 3,889 ); and, finally, a thioesterase, or termination, domain (COG3319; residues 3,922 to 4,187). Between the acyl transferase domain and the ACP domain, the sequence exhibits similarity to dehydratase (DH) and $\beta$-ketoreductase (KR) domains of type I polyketide synthetases (Fig. 5A and B). The conserved consensus motifs GxGxxGxxxA and $\operatorname{Lx}(\mathrm{S}, \mathrm{G}) \mathrm{Rx}(\mathrm{G}, \mathrm{T}, \mathrm{A})$ implicated in NADP(H)-binding (Scrutton et al. 1990) are present in the KR-like sequence, which has $38 \%$ identical and $44 \%$ conserved amino acid residues compared with, for example, the KR domain of module 4 of the erythronolide synthetase of Saccharopolyspora erythraea (accession number Q03132), indicating that $s y l D$ encodes an active KR. The sequence between amino acids 2,397 and 2,601 in the sylD protein has $32 \%$ identical (40\% conserved) amino acids compared with the dehydratase domain of the erythronolide synthetase module mentioned above (Bevitt et al. 1992). However, the conserved motif around the active site histidine residue (LxxHxxxGxxxxP) of dehydratases (Donadio and Katz 1992)

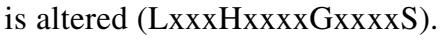

The plasmid insertion interrupts the encoded protein after amino acid 851 within the adenylation domain of the first module. In conclusion, sylC and $s y l D$ together encode three typical NRPS modules which could account for the activation and condensation of the three amino acids contained in syringolin A, which are connected by peptide bonds. However, the module activating the first amino acid in peptides synthesized by NRPS usually does not contain a condensation domain (Marahiel et al. 1997), whereas all three modules encoded by sylC and sylD exhibit such a domain. A possible function of the polyketide synthetase-like module is discussed below.
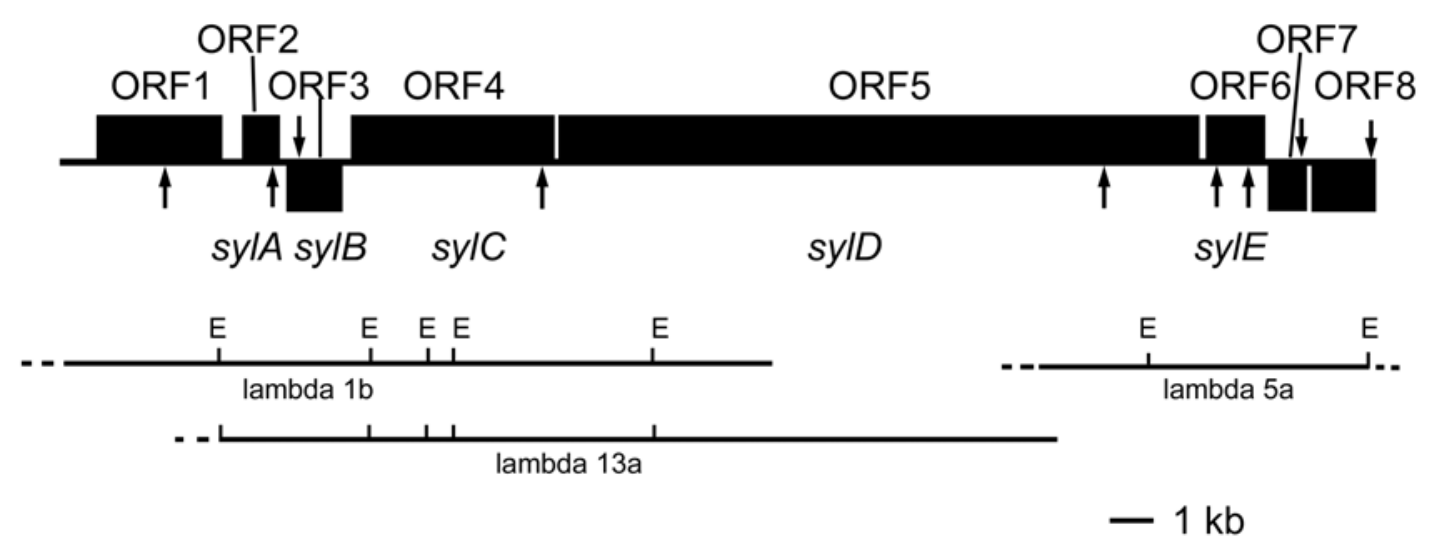

Fig. 3. Arrangement of open reading frames (ORFs) and syringolin A synthetase genes. The top line represents the sequenced 25-kb genomic region of Pseudomonas syringae pv. syringae (accession no. AJ548826). ORFs on top and bottom strands are indicated by thick bars above and below the line, respectively. ORFs are numbered according to the text. ORFs affecting syringolin A production when mutated have been labeled as syl genes below the corresponding bars. The position of plasmid insertions in the mutants are indicated by arrows. A contig of overlapping lambda clones from which the sequence was derived is shown below the gene representation. Dashed lines indicate clone segments of unknown length that were not sequenced. E, EcoRI restriction site. 
The $s y l E$ gene product may be involved in syringolin A export.

The putative protein encoded by $s y l E$ consists of 411 aa (nucleotide position 22,364 to 23,596) and a predicted molecular weight of 43,298 Da. The most similar sequence in the SWISSPROT protein sequence database is the tetracycline efflux transporter TCR3_ECOLI (accession number P02981), with which it shares $44 \%$ identical and conserved amino acids over its entire length. Thus, it seems likely that $s y l E$ is involved in the secretion of syringolin A. The insertion mutant still accumulated reproducibly approximately $20 \%$ of the syringolin A concentration of the wild type grown under identical conditions (data not shown). This may indicate that the putative transporter encoded by $s y l E$ is functionally, in part, redundant; or, alternatively, that the mutated transporter, which is interrupted after amino acid residue 309, retains partial activity. To discriminate between these possibilities, a $s y l E$ null mutant was constructed in which nearly the complete $s y l E$ gene was replaced by a kanamycine resistance gene cassette. This mutant showed a phenotype identical to the sylE insertion mutant (i.e., it accumulated approximately $20 \%$ of syringolin A compared with the wild type, indicating the sylE transporter function is, in part, redundant). This result is important because $s y l C$, sylD, and sylE are positioned in sequence on the same DNA strand and may constitute an operon. Thus, the mutant phenotype of insertions in $s y l C$ and $s y l D$, which encode peptide synthesis modules, could have been the result of a polar effect on $s y l E$. This is ruled out because the $s y l E$ gene replacement mutant exhibits a phenotype clearly distinguished from the one shown by the sylC and sylD insertion mutants.

\section{Likely functions of the $s y l A$ and $s y l B$ gene products.}

sylA encodes a putative protein of 238 aa residues (nucleotide position 3,504 to 4,217 ) and a predicted molecular weight of 26,434 Da. It contains the conserved HTH_LUXR domain (SMART accession number SM0421; pfam00196; residues 176 to 336) at its C-terminus. This helix-turn-helix DNA-binding domain is found in two classes of transcriptional activators: one class comprises the autoinducer binding transcriptional activators of the LuxR family, where it is located at the C-terminus; the other class contains transcriptional activator components of bacterial two-component regulatory systems. Thus, the putative $s y l A$ gene product likely is a transcription regulator involved in the activation of syringolin A synthetase genes. Interruption of the $s y l A$ gene by plasmid insertion into the codon of amino acid residue 206, which is in the middle of the conserved HTH_LUXR DNA binding domain, abolishes syringolin A accumulation in the medium (data not shown).

The putative protein of 350 aa encoded by the $s y l B$ gene (nucleotide position 4,375 to 5,424 ) exhibits a conserved fatty acid desaturase domain (pfam00487; residues 58 to 282). The $s y l B$ gene product is most similar in sequence (35\% identical and $47 \%$ conserved amino acid residues) to the $r t x C$ gene (accession number AB062279) product of Bradyrhizobium elkanii, which also contains the pfam00487 domain (Fig. 5C). RtxC is involved in the biosynthesis of rhizobitoxine, an $\alpha$-amino acid derivative (Yasuta et al. 2001). Experimental evidence was provided indicating that the $r t x C$-encoded enzyme introduces a double bond between the $\mathrm{C} 3$ and $\mathrm{C} 4$ atoms of dihydrorhizobitoxine (Yasuta et al. 2001). There are two carbon-carbon double bonds in syringolin A: One in the 3,4-dehydrolysine residue, the other in the 5methyl-4-amino-2-hexenoic acid residue. Thus, it appears likely that the $s y l B$ gene product is responsible for the introduction of the double bond into one of these moieties. We favor the hypothesis that $s y l B$ is responsible for the desaturation of the lysine residue to 3,4-dehydrolysine for reasons given below.

\section{DISCUSSION}

Syringolin consists of the tripeptide (valine)-(2,3,-dehydrolysine)-(5-methyl-4-amino-2-hexenoic acid) and an additional

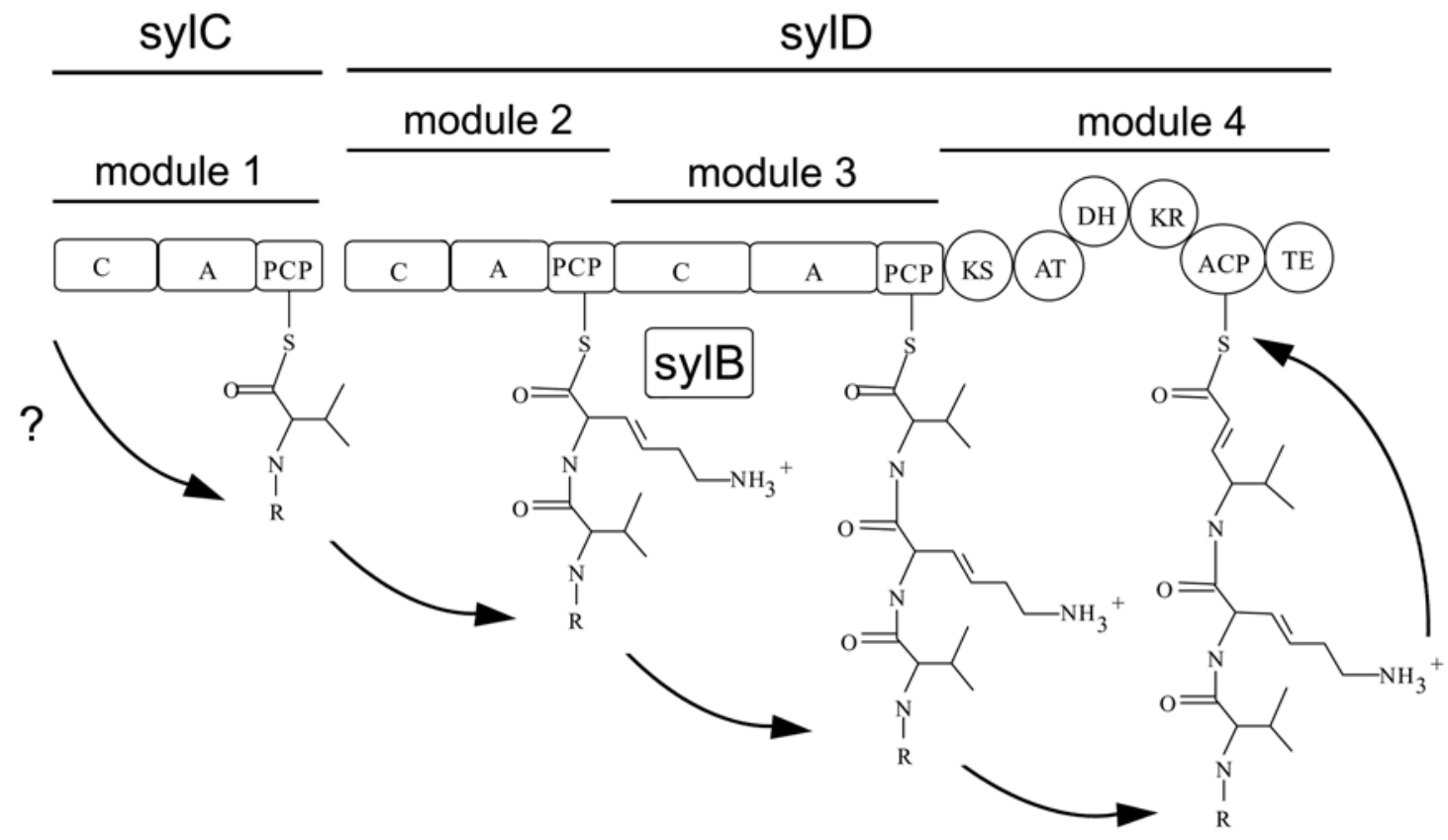

Fig. 4. Model for the biosynthesis of syringolin A based on the structure of the syl gene cluster. The condensation, activation, and peptide carrier protein domains of the peptide synthetase modules encoded by $s y l C$ and $s y l D$ are represented by boxes labeled with C, A, and PCP, respectively. Putative $\beta$ ketoacyl synthetase (KS), acyl transferase (AT), dehydratase (DH), $\beta$-ketoreductase (KR), acyl carrier protein (ACP), and thioesterase (TE) domains of the polyketide-like module also encoded by sylD are represented as circles. Arrows indicate the sequential reactions suggested by the gene structure. $\mathrm{R}$ denotes the N-ureido-valine whose synthesis and activation is not accounted for by the model. This uncertainty is indicated by the question mark at the first step depicted in the figure. The last arrow indicates the cyclization step presumably achieved by the TE domain. SylB is depicted as a box near the dehydrolysine residue because it is supposed to desaturate the lysine residue hypothesized to be activated by module 2 . However, it is not known at which stage of syringolin A synthesis this reaction may occur. 
valine residue that is linked to the N-terminal valine of the tripeptide via a ureido group. Because the sequence in which the NRPS modules are encoded on the chromosome generally determines the amino acid sequence of the peptide product, the sylC-encoded module is suggested to activate valine, whereas the two NRPS modules encoded by sylD should activate lysine (or dehydrolysine) and 5-methyl-4-amino-2-hexenoic acid (or its precursor), respectively. As detailed below, we suggest that valine is the activated precursor of 5-methyl-4-amino-2-hexenoic acid.

In addition to the two NRPS modules composing the N-terminal part of the $s y l D$ gene product, a module typical of type I polyketide synthetases is located in the C-terminal part. We hypothesize that the 5-methyl-4-amino-2-hexenoic acid residue contained in the ring structure of syringolin $\mathrm{A}$ is synthesized

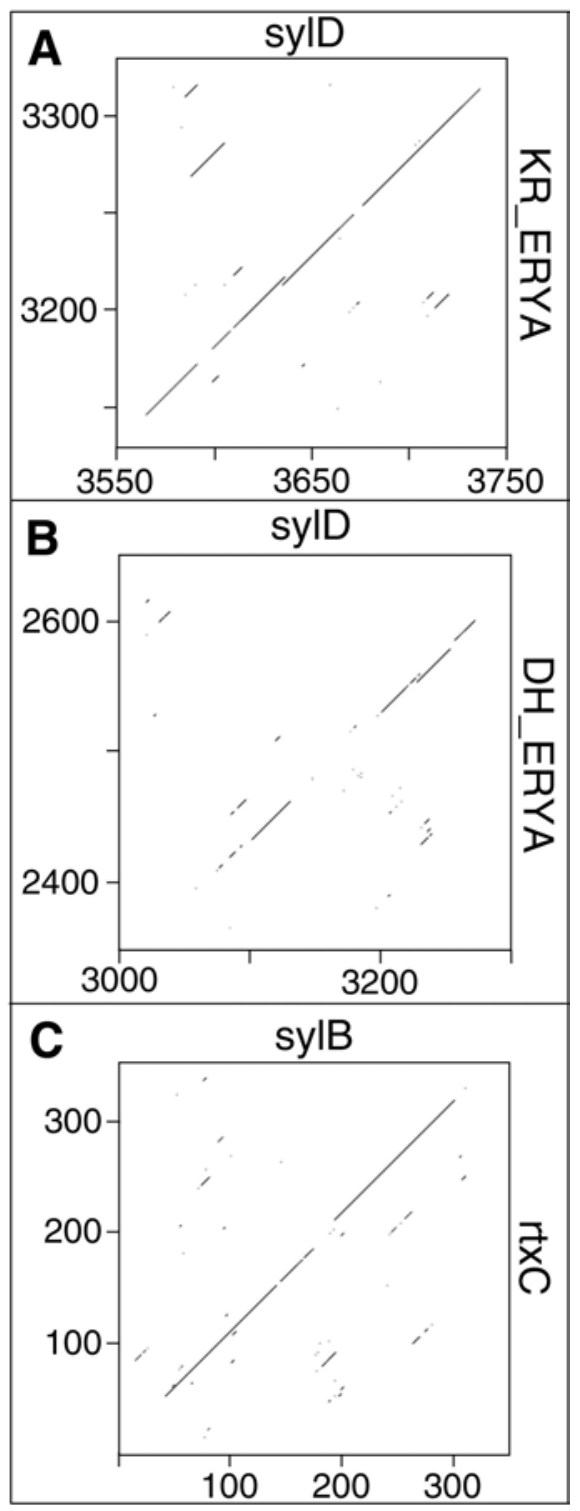

Fig. 5. Dot plot analysis of amino acid sequences encoded by $s y l D$ and sylB. SylD encoded sequences were compared with $\mathbf{A}$, the $\beta$ ketoreductase domain (KR_ERYA) and B, the dehydratase domain (DH_ERYA) of module 4 of the erythronolide synthetase of Saccharopolyspora erythraea (accession number Q03132). C, The complete protein sequences encoded by the $s y l B$ and $r t x C$ genes were compared. Numbers refer to amino acid positions in the protein sequences. The plots were calculated with the compare and dot plot programs of the Wisconsin Package Version 10.1, Genetics Computer Group, Madison, WI, U.S.A. from valine, which would be activated by the second NRPS module encoded by $s y l D$ (Fig. 4). Condensation to an activated malonyl moiety on the ACP of the PKS module and decarboxylation would extend the molecule by a two-carbon unit and lead to a diketide, which would be reduced by the $\beta$-ketoreductase and the dehydratase domains to the 5-methyl-4amino-2-hexenoic acid moiety. Release and ring formation between the terminal carboxyl group and the $\varepsilon$-amino group of the 3,4-dehydrolysine would be mediated by the thioesterase domain (Fig. 4).

The above considerations explain the presence of the double bond in the 5-methyl-4-amino-2-hexenoic acid moiety, and thus make it likely that the sylB protein, which exhibits similarity to the rhizobitoxine desaturase, is involved in the formation of the dehydrolysine residue containing the other double bond present in syringolin. As described earlier (Wäspi et al. 1999), P. syringae pv. syringae B301D-R produces a whole family of compounds related to syringolin $\mathrm{A}$, the major variant. Minor variants differ in containing lysine instead of 3,4-dehydrolysine (syringolin $\mathrm{B}$, the third most abundant variant), or isoleucine instead of valine at one or both positions, and almost all possible combinations of these substitutions. It was hypothesized that all these variants are synthesized by the same synthetase, which would incorporate with a certain probability isoleucine instead of valine, and which would desaturate lysine with incomplete efficiency (Wäspi et al. 1999). If $s y l B$ would, indeed, be responsible for desaturating the lysine residue, one may expect the abundance of syringolin B to increase at the expense of syringolin A. However, the $s y l B$ insertion mutant, in which the encoded putative protein is interrupted at amino acid residue 39, has lost its syringolin A production (data not shown), and no increase of a peak corresponding to syringolin $\mathrm{B}$ could be observed (data not shown). Thus, it is clear that syringolin A essentially was not converted into syringolin B in the $s y l B$ insertion mutants. This result is still compatible with the hypothesis that $s y l B$ encodes the lysine reductase because the absence of a wild-type $s y l B$ protein may have impaired the assembly of the functional syringolin A synthetase.

Based on the known structure of the PheA domain of the GrsA peptide synthetase complexed with AMP and phenylalanine, the selectivity-conferring code of domains activating a variety of substrates and substrate-specific rules for binding pockets have been derived (Challis et al. 2000, Stachelhaus et al. 1999). Alignment analysis of the activating domain encoded by $s y l C$ showed that the relevant signature residues are very similar to one of the valine signatures (Val 1) (Table 1), whereas the first activating domain encoded by $s y l D$, which we hypothesize to activate lysine, has acidic residues at positions in the binding pockets projected to interact with the basic side chain of the bound substrate (Table 1) (Stachelhaus et al. 1999). The corresponding residues of the second activating domain encoded by sylD which, according to our hypothesis, is expected to activate valine, do not conform to any of the published signatures (Challis et al. 2000; Stachelhaus et al., 1999). However, the aliphatic or polar characters of these residues seem compatible with a binding pocket specific for valine (Table 1). Thus, we hypothesize that the synthesis of the tripeptide contained in syringolin A occurs according to the scheme depicted in Figure 4. The hypothesis does not explain the presence of the valine which is linked to the N-terminus of the tripeptide via the ureido group. It seems likely that the condensation domain encoded by sylC is involved in this. At present, the mechanism of synthesis and activation of this moiety remains unknown.

$s y l C, s y l D$, and $s y l E$ are positioned close to each other on the same DNA strand and, thus, possibly form an operon (Fig. 3). It seems unlikely that $s y l A$ may also be part of the same operon, 
because it is separated from the former three ORFs by $s y l B$, which is positioned on the opposite strand. If $s y l C$, $s y l D$, and $s y l E$ indeed are part of an operon, insertions in the upstream cistrons may have polar effects on the downstream cistrons, and one could argue that the sylE transporter is important for syringolin accumulation in the medium, but that the sylC and sylD peptide synthesis modules have no part in syringolin A biosynthesis. This can be ruled out by the fact that the sylE gene replacement mutant still accumulated $20 \%$ syringolin, whereas the insertion mutants in $s y l C$ and $s y l D$ did not. Further experiments have to be performed to determine whether these three genes indeed form an operon or are transcribed separately, and to define regulatory elements in the gene cluster.

SylA encodes a protein with a HTH_LUXR DNA binding domain, suggesting that this protein is involved in the transcriptional regulation of $s y l$ genes. A subfamily of this class of transcriptional activators is regulated by autoinducers and contains an autoinducer biding domain (pfam03472) at the N-terminus. However, sylA protein does not contain a conserved autoinducer domain. Thus, it seems more likely that this putative transcription regulator is part of a two-component regulatory system, but further experiments must be performed to definitely assess its detailed function.

Recently, the unfinished genomic sequence of $P$. syringae pv. syringae $\mathrm{B} 728 \mathrm{a}$ became available (accession number NZ_AABP02000000). Except for sylA, all ORFs described in this work have been found by automatic identification by the sequencing group. They encode predicted proteins of identical length and nearly identical sequence ( $>99 \%$ identity; accession numbers ZP-00124545.1 [sylB], ZP-00124544.1 [sylC], ZP00124542.1 [sylD], and ZP-00124541.1 [sylE]; all encoded by the contig with the accession number NZ_AABP02000001). SylA was not predicted, but the corresponding DNA sequence of strain B728a encodes a putative protein of identical length that exhibits $97.5 \%$ sequence identity. We were not able to identify other predicted ORFs in the greater vicinity of the $s y l$ genes in the B728a genome, which may be involved in the formation of the ureido-valine moiety of syringolin A in an obvious way.

As previously noted (Wäspi et al. 1998), the only compounds known so far with a structure similar to the one of syringolins are glidobactins and cepafungins, which form a family of closely related antitumor antibiotics isolated from the gram-negative bacterium Polyangium brachysporum (Oka et al. 1988a and b) and from Pseudomonas spp. (Shoji et al. 1990; Terui et al. 1990). The 12-membered ring structure of these tripeptides consists of the two amino acids 4-hydroxylysine and 4-amino-2-pentenoic acid. The extracyclic amino acid is Lthreonine, whose terminal amine is acylated by different unsaturated fatty acids, which are essential for the antibiotic activity (Oka et al. 1988a). The tripeptide part of these molecules likely is synthesized by an enzyme similar to the syringolin A synthetase. The 4-amino-2-pentenoic acid may be produced in the same way as proposed for the 5-methyl-4-amino-2-hexenoic acid moiety in syringolin A, except that alanine instead of valine is used as the substrate of the $\beta$-ketoacyl synthase domain. In addition, 4-hydroxylysine may be the product of an oxidase similar to sylB, which, however, would not perform the elimination of water. The cloning of the syringolin A synthetase genes reported in this work may open up the possibility of engineering molecules containing the rare 12-membered ring structure present in syringolins and glidobactins with interesting antibiotic or antitumor properties.

The identification of genes involved in the biosynthesis of syringolin A and the availability of syringolin A-negative mutants will be of great value for functional studies of the interaction of syringolin A-producing strains with their hosts.

\section{MATERIALS AND METHODS}

Isolation of $P$. syringae pv. syringae genomic DNA.

$P$. syringae pv. syringae $\mathrm{B} 301 \mathrm{D}-\mathrm{R}$ were grown in $50 \mathrm{ml}$ of $2 \times$ TY medium (16 $\mathrm{g}$ of tryptone, $10 \mathrm{~g}$ of yeast extract, $5 \mathrm{~g}$ of $\mathrm{NaCl})$ in a shaker $(250 \mathrm{rpm})$ at $28^{\circ} \mathrm{C}$ for $24 \mathrm{~h}$. Bacteria were collected by centrifugation and resuspended in $15 \mathrm{ml}$ of lysis buffer (25 mM Tris- $\mathrm{mCl}, \mathrm{pH} 8,25 \mathrm{mM}$ sucrose, $10 \mathrm{mM}$ EDTA) and incubated for $15 \mathrm{~min}$ at room temperature after the addition of lysozyme to a final concentration of $10 \mathrm{mg} / \mathrm{ml}$. After sodium dodecyl sulfate and proteinase $\mathrm{K}$ were added to final concentrations of $1 \%(\mathrm{wt} / \mathrm{vol})$ and $100 \mu \mathrm{g} / \mathrm{ml}$, respectively, the suspension was incubated for $1 \mathrm{~h}$ at $37^{\circ} \mathrm{C}$ and then for 15 $\min$ at $55^{\circ} \mathrm{C}$. The lysate was extracted first with 1 volume of phenol, then with 1 volume of phenol/chloroform/isoamylacohol (19:19:1), and finally with 1 volume of chloroform. Nucleic acids were precipitated with two volumes of ethanol, washed with $70 \%$ ethanol at $4^{\circ} \mathrm{C}$, and dissolved in TE $(10 \mathrm{mM}$ Tris-HCl, $\mathrm{pH}$ 8, 1 mM EDTA).

\section{PCR amplification and cloning of peptide synthetase fragments.}

Degenerate oligonucleotide pools TGD1 (5'-ACIGGIGA $(\mathrm{C}, \mathrm{T}) \mathrm{CTIGCI}(\mathrm{A}, \mathrm{C})$ and LGG1 (5'-(C,T)TTIA(A,G)I(C,G) $(\mathrm{A}, \mathrm{T})(\mathrm{A}, \mathrm{G}) \mathrm{T}(\mathrm{C}, \mathrm{G}) \mathrm{ICCICC})$ were synthesized and used as primers in a $\mathrm{PCR}$ reaction with $P$. syringae pv. syringae genomic DNA as a template. The reaction volume was $100 \mu \mathrm{l}$ and contained $5 \mathrm{ng}$ of genomic DNA, $20 \mu \mathrm{M}$ dNTP, $1 \mu \mathrm{M}$ TGD1, 2 $\mu \mathrm{M}$ LGG1, 5\% dimethyl sulfoxide, $2.5 \mathrm{U}$ of Taq DNA polymerase (Amersham Pharmacia Biotech, Little Chalfont, U.K.), and $10 \mu \mathrm{l}$ of $10 \times$ PCR buffer (Amersham Pharmacia Biotech). A touch-down cycle program was employed using the following parameters: a single cycle of $1 \mathrm{~min}$ at $94^{\circ} \mathrm{C}, 1 \mathrm{~min}$ at $51^{\circ} \mathrm{C}$, and $1 \mathrm{~min}$ at $72^{\circ} \mathrm{C}$, followed by single cycles with annealing temperatures of $49,47,45$, and $43^{\circ} \mathrm{C}$, respectively, followed by 30 identical cycles with an annealing temperature of $41^{\circ} \mathrm{C}$. The PCR products were separated on a $1.5 \%$ agarose gel, and a band of approximately $500 \mathrm{bp}$, the expected size, was eluted with the gel extraction kit (Qiagen, Basel, Switzerland). The corresponding DNA fragments were cloned into the pGEM-T Easy vector (Promega Corp., Madison, WI, U.S.A.).

Table 1. Amino acid residues at signature positions in the activating domains encoded by $s y l C$ and $s y l D$

\begin{tabular}{lcccccccccc}
\hline & \multicolumn{10}{c}{ Position $^{\mathbf{a}}$} \\
\cline { 2 - 7 } Domain $^{\mathbf{b}}$ & $\mathbf{2 3 5}$ & $\mathbf{2 3 6}$ & $\mathbf{2 3 9}$ & $\mathbf{2 7 8}$ & $\mathbf{2 9 9}$ & $\mathbf{3 0 1}$ & $\mathbf{3 2 2}$ & $\mathbf{3 3 0}$ & $\mathbf{3 3 1}$ & $\mathbf{5 1 7}$ \\
\hline Val1 & D & A & F & W & I & G & G & T & F & K \\
SylC (Val) & D & A & F & W & L & G & C & V & F \\
SylD1 (Lys) & D & V & S & E & R & L & V & C & E & K \\
SylD2 (Val) & D & G & G & Q & I & A & G & V & Y & K \\
\hline
\end{tabular}

a Amino acid positions refer to the PheA domain of the GrsA peptide synthetase and were derived from multiple sequence alignments (Stachelhaus et al. 1999).

${ }^{\mathrm{b}}$ The proposed cognate amino acids of activating domains are given in parentheses. Val1 refers to valine signature 1 (Stachelhaus et al. 1999) and SylD1 and SylD2 denote the first and second module encoded by sylD, respectively. 
Cloning and sequencing of the genomic region containing syringolin A synthetase genes.

To produce a genomic library of $P$. syringae pv. syringae B301D-R, genomic DNA was subjected to limited Sau3A digestion and DNA fragments in the $15-$ to $20-\mathrm{kb}$ size range were isolated according to standard procedures (Maniatis et al. 1982) and cloned into BamHI predigested lambda DASH II vector arms (Stratagene, La Jolla, CA, U.S.A.). Phage DNA was packaged with the Gigapack Gold packaging kit (Stratagene) according to procedures given by the manufacturer. The library was screened and phage DNA was isolated according to standard procedures (Maniatis et al. 1982) using radiolabeled pPS3 insert as a probe. Overlapping lambda clones were identified with DNA fragments derived from the ends of lambda clone inserts used as probes. Sequencing was performed on an ABI 377 machine (PE Biosystems, Foster City, CA, U.S.A.) using the BigDye terminator cycle sequencing kit (v2.0; PE Biosystems). In general, EcoRI fragments of lambda clones were subcloned in pBluescript (Stratagene) and sequenced. The order of EcoRI fragments was determined by sequencing PCR-amplified fragments obtained with primers derived from the ends of the EcoRI fragments using lambda phage DNA as the template. Both strands were sequenced at least once.

\section{Construction of mutants.}

Putative syringolin A synthetase-encoding genes of $P$. syringae pv. syringae B301D-R were interrupted in the coding region by insertion of a plasmid containing a DNA fragment derived from the putative gene by homologous recombination. Gene fragments (discussed below) were cloned into the suicide vector pME3087 (Tc'r; ColE1 replicon; EcoRI KpnI BamHI XbaI PstI SphI HindIII polylinker) (Voisard et al. 1994). Recombinant plasmids were transformed into E. coli S17-1 (thi pro hsdR recA; chromosomal $\mathrm{RP} 4\left[\mathrm{Tra}^{+} \mathrm{Tc}^{\mathrm{s}} \mathrm{Km}^{\mathrm{s}} \mathrm{Ap}{ }^{\mathrm{s}}\right]$ ) and mobilized to $P$. syringae pv. syringae B301D-R. P. syringae pv. syringae colonies carrying chromosomally integrated plasmids were selected for tetracycline resistance. First, the PS3 PCR fragment was cut out from pGEM-T Easy with EcoRI and subcloned into the EcoRI cloning site of pME3087. Except for sylD, for which a genomic EcoRI-HindIII fragment was subcloned, suitable fragments contained in the ORFs were PCR amplified from cloned or genomic DNA with specific forward and backward primers with EcoRI and HindIII restriction sites added, respectively, and cloned into the respective polylinker sites of pME3087. The fragments cloned into pME3087 corresponded to the following genomic regions: ORF 1: 1,288 to 1,902; sylA: 3,579 to 4,123 ; sylB: 4,555 to 5,308 ; sylC: 8,991 to 9,$469 ;$ sylD: 11,555 to 12,270 ; sylE: 22,545 to 23,290 ; ORF 7: 23,707 to 24,248 ; ORF $8: 24,577$ to 25,521 . Thus, integration of these plasmids by homologous recombination should create duplicated copies of the sequence corresponding to the cloned fragment which are separated by the vector. The position of the vector in the genomic DNA was verified for each mutant by sequencing a PCR fragment that was obtained with a forward primer located upstream of the cloned fragment and a reverse primer derived from pME3087 sequence outside the polylinker neighboring the HindIII site (pr_3087; 5'-GAGAAATCACCAT GAGTG). Two independent colonies for each mutant always were verified and used in further experiments.

To obtain a sylE gene replacement mutant, two PCR fragments (A and B) flanking the $s y l E$ gene were joined. They corresponded to nucleotide position 21,884 to 22,492 and 23,601 to 24,248 , respectively, of the sequenced genomic region. The PCR primers were designed in a way that provided a Bam $\mathrm{HI}$ site between the joined fragments as well as an EcoRI and a HindIII site at the two ends, respectively. The fragment, whose sequence was verified, was cloned between the EcoRI and HindIII sites of pME3087 (named pAB), and its sequence was verified. A 2.2-kb Bam HI fragment carrying a kanamycin resistance cassette was cut out from $\mathrm{pHP} 45 \Omega-\mathrm{km}$ (Fellay et al. 1987 ) and cloned into the unique BamHI site of pAB to yield pAkmB. Thus, the insert of pAkmB contained a genomic region from which most of the sylE gene (nucleotide position 22,493 to 23,600 ; i.e., all except the sequence encoding the first 43 aa) was replaced by the kanamycin resistance gene. pAkmB was transformed into E. coli S-17 and mobilized into $P$. syringae pv. syringae. Double homologous recombinants exhibiting kanamycin resistance and tetracycline sensitivity were selected and verified by genomic DNA gel blot analysis.

\section{Analysis of syringolin A, syringomycin, and syringopeptin in conditioned media.}

To induce syringolin A production, $P$. syringae pv. syringae B301D-R was cultured in $2 \mathrm{ml}$ of $2 \times \mathrm{TY}$ in a shaker $(250 \mathrm{rpm})$ at $28^{\circ} \mathrm{C}$ overnight. The culture then was diluted in $\mathrm{SRM}_{\mathrm{AF}}$ (Gross 1985; Mo and Gross 1991a and b) to an optical density of 0.05 . For routine analysis, $0.5 \mathrm{ml}$ of this dilution was used to inoculate $50 \mathrm{ml}$ of $\mathrm{SRM}_{\mathrm{AF}}$. Following an incubation without shaking at $28^{\circ} \mathrm{C}$ for 5 to 7 days, conditioned media were separated from bacteria by centrifugation at $12,000 \times g$ for $15 \mathrm{~min}$. Media were analyzed directly or frozen at $-20^{\circ} \mathrm{C}$ until used.

In a standard assay, $1 \mathrm{ml}$ of conditioned medium was filtrated through a Millex GP filter unit $(0.22-\mu \mathrm{m}$ pore size; Millipore, Molsheim, France) and acidified by the addition of $3 \mu \mathrm{l}$ of trifluoroacetic acid (TFA), after which $200 \mu \mathrm{l}$ was loaded onto an ET 250/4 Nucleosil 100-5 C18 column (Macherey Nagel, Düren, Germany), which was connected to a Gynkotek model P 580 HPG HPLC pump (Dionex, Sunnyvale, CA, U.S.A.) and a UVIS 204 detector (Linear Instruments Corp., Reno, NV, U.S.A.). The column was equilibrated with $0.06 \%$ TFA in HPLC-grade water. Isocratic separation was performed in $50 \%$ acetonitrile, $0.06 \%$ TFA at a flow rate of $1 \mathrm{ml} / \mathrm{min}$ and the absorption at $206 \mathrm{~nm}$ was monitored with a Millipore $212 \mathrm{CR}$ recorder. Syringolin A, identified by using syringolin A isolated as described (Wäspi et al. 2001) as a standard, eluted at approximately $10 \mathrm{~min}$ under these conditions.

As a control for correct inducing conditions, conditioned media also were checked for their content of syringomycin and syringopeptin. As standards, these compounds were extracted with butanol from conditioned media treated with acetone (Gross and DeVay 1977). Mass spectrometry of the two most prominent compounds revealed masses of 1,225 and 2,144, suggesting that they represented syringomycin E (Segre et al. 1989) and syringopeptin $\mathrm{SP}_{22}$-A (Ballio et al. 1991), respectively. Mass spectrometry was kindly performed by P. Hunziker, Institute of Biochemistry, University of Zurich, on a PerkinElmer/Sciex API III ${ }^{+}$instrument.

The presence of these two compounds in conditioned media used for syringolin A measurements of syringolin A mutants always was checked with an abbreviated procedure as a positive control for the induction conditions. Thus, in a standard assay, $2 \mathrm{ml}$ of conditioned medium was sterile filtrated as described above, acidified with $10 \mu \mathrm{l}$ of $12 \mathrm{~N} \mathrm{HCl}$, and mixed with $2 \mathrm{ml}$ of acetone. After shaking for $10 \mathrm{~min}$, the sample was evaporated at $40^{\circ} \mathrm{C}$ and taken up in $2 \mathrm{ml}$ of $30 \%$ (vol/vol) acetonitrile in water. After a 5 min-centrifugation at 14,000 $\times g, 1$ $\mathrm{ml}$ was subjected to HPLC analysis using equipment and conditions described above.

\section{ACKNOWLEDGMENTS}

We thank C. Reimmann and D. Haas for bacterial strains, vectors, and advice; P. Hunziker for help with mass spectrometry; D. C. Gross for the 
kind gift of Pseudomonas syringae B301D-R; and K. Michel, S. Rau, and S. Kronenberg for expert technical assistance.

\section{LITERATURE CITED}

Ballio, A., Barra, D., Bossa, F., Collina, A., Grgurina, I., Marino, G., Moneti, G., Paci, M., Pucci, P., and Segre, A. 1991. Syringopeptins, new phytotoxic lipodepsipeptides of Pseudomonas syringae pv. syringae. FEBS (Fed. Eur. Biochem. Soc.) Lett. 291:109-12.

Bevitt, D. J., Cortes, J., Haydock, S. F., and Leadlay, P. F. 1992. 6-Deoxyerythronolide-B synthase-2 from Saccharopolyspora erythraeaCloning of the structural fene, sequence analysis and inferred domain structure of the multifunctional enzyme. Eur. J. Biochem. 204:39-49.

Challis, G. L., Ravel, J., and Townsend, C. A. 2000. Predictive, structurebased model of amino acid recognition by nonribosomal peptide synthetase adenylation domains. Chem. Biol. 7:211-224.

Donadio, S., and Katz, L. 1992. Organization of the enzymatic domains in the multifunctional polyketide synthase involved in erythromycin formation in Saccharopolyspora erythraea. Gene 111:51-60.

Fellay, R., Frey, J., and Krisch, H. 1987. Interposon mutagenesis of soil and water bacteria: a family of DNA fragments designed for in vitro insertional mutagenesis of gram-negative bacteria. Gene 52:147-152.

Gross, D. C. 1985. Regulation of syringomycin synthesis in Pseudomonas syringae pv. syringae and defined conditions for its production. J. Appl. Bacteriol. 58:167-174.

Gross, D. C., and DeVay, J. E. 1977. Role of syringomycin in holcus spot of maize and systemic necrosis of cowpea caused by Pseudomonas syringae. Physiol. Plant Pathol. 11:1-11.

Guenzi, E., Galli, G., Grgurina, I., Gross, D. C., and Grandi, G. 1998. Characterization of the syringomycin synthetase gene cluster-A link between prokaryotic and eukaryotic peptide synthetases. J. Biol. Chem. 273:32857-32863.

Hopwood, D. A. 1997. Genetic contributions to understanding polyketide synthases. Chem. Rev. 97:2465-2497.

Hrabak, E. M., and Willis, D. K. 1992. The lemA gene required for pathogenicity of Pseudomonas syringae pv. syringae on bean is a member of a family of two-component regulators. J. Bacteriol. 174:3011-3020.

Hrabak, E. M., and Willis, D. K. 1993. Involvement of the lemA gene in production of syringomycin and protease by Pseudomonas syringae pv. syringae. Mol. Plant-Microbe Interact. 6:368-375.

Maniatis, T., Fritsch, E. F., and Sambrook, J. 1982. Molecular Cloning. A Laboratory Manual Cold Spring Harbor Laboratory Press, Cold Spring Harbor, NY, U.S.A

Marahiel, M. A., Stachelhaus, T., and Mootz, H. D. 1997. Modular peptide synthetases involved in nonribosomal peptide synthesis. Chem. Rev. 97:2651-2673.

Mo, Y. Y., and Gross, D. C. 1991a. Expression in vitro and during plant pathogenesis of the $s y r B$ gene required for syringomycin production by Pseudomonas syringae pathovar syringae. Mol. Plant-Microbe Interact. 4:28-36.

Mo, Y.-Y., and Gross, D. C. 1991b. Plant signal molecules activate the $s y r B$ gene, which is required for syringomycin production by Pseudomonas syringae pv. syringae. J. Bacteriol. 173:5784-5792.

Oka, M., Nishiyama, Y., Ohta, S., Kamei, H., Konishi, M., Miyaki, T., Oki, T., and Kawaguchi, H. 1988a. Glidobactins A, B and C, new antitumor antibiotics. I. Production, isolation, chemical properties and biological activity. J. Antibiot. 41:1331-1337.
Oka, M., Yaginuma, K., Numata, K., Konishi, M., Oki, T., and Kawaguchi, H. 1988b. Glidobactins A, B and C, new antitumor antibiotics. II. Structure elucidation. J. Antibiot. 41:1338-1350.

Reimmann, C., Hofmann, C., Mauch, F., and Dudler, R. 1995. Characterization of a rice gene induced by Pseudomonas syringae pv. syringae: Requirement for the bacterial lemA gene function. Physiol. Mol. Plant Pathol. 46:71-81.

Rich, J. J., Kinscherf, T. G., Kitten, T., and Willis, D. K. 1994. Genetic evidence that the gacA gene encodes the cognate response regulator for the lemA sensor in Pseudomonas syringae. J. Bacteriol. 176:7468-75.

Scholz-Schroeder, B. K., Soule, J. D., and Gross, D. C. 2003. The sypA, syp $B$, and syp $C$ synthetase genes encode twenty-two modules involved in the nonribosomal peptide synthesis of syringopeptin by Pseudomonas syringae pv. syringae B301D. Mol. Plant-Microbe Interact. 16:271-280.

Scrutton, N. S., Berry, A., and Perham, R. N. 1990. Redesign of the coenzyme specificity of a dehydrogenase by protein engineering. Nature 343:38-43.

Segre, A., Bachmann, R. C., Ballio, A., Bossa, F., Grgurina, I., Iacobellis, N. S., Marino, G., Pucci, P., Simmaco, M., and Takemoto, J. Y. 1989. The structure of syringomycins A1, E and G. FEBS (Fed. Eur Biochem. Soc.) Lett. 255:27-31.

Shoji, J., Hinoo, H., Kato, T., Hattori, T., Hirooka, K., Tawara, K., Shiratori, O., and Terui, Y. 1990. Isolation of cepafungins I, II and III from Pseudomonas species. J. Antibiot. 43:783-787.

Stachelhaus, T., and Marahiel, M. A. 1995. Modular structure of peptide synthetases revealed by dissection of the multifunctional enzyme Grsa. J. Biol. Chem. 270:6163-6169.

Stachelhaus, T., Mootz, H. D., and Marahiel, M. A. 1999. The specificityconferring code of adenylation domains in nonribosomal peptide synthetases. Chem. Biol. 6:493-505.

Terui, Y., Nishikawa, J., Hinoo, H., Kato, T., and Shoji, J. 1990. Structures of cepafungins I, II and III. J. Antibiot. 43:788-795.

Turgay, K., and Marahiel, M. A. 1994. A general approach for identifying and cloning peptide synthetase genes. Pept. Res. 7:238-41.

Voisard, C., Bull, C. T., Keel, C., Laville, J., Maurhofer, M., Schnider, U., Défago, G., and Haas, D. 1994. Biocontrol of root diseases by Pseudomonas fluorescens CHA0: current concepts and experimental approaches. Pages 67-89 in: Molecular Ecology of Rhizosphere Microorganisms. F. O'Gara, D. Dowling, and B. Boesten, eds. VCH Publishers, Weinheim, Germany.

Wäspi, U., Blanc, D., Winkler, T., Ruedi, P., and Dudler, R. 1998. Syringolin, a novel peptide elicitor from Pseudomonas syringae pv. syringae that induces resistance to Pyricularia oryzae in rice. Mol. PlantMicrobe Interact. 11:727-733.

Wäspi, U., Hassa, P., Staempfli, A., Molleyres, L.-P., Winkler, T., and Dudler, R. 1999. Identification and structure of a family of syringolin variants: Unusual cyclic peptides from Pseudomonas syringae pv. syringae that elicit defense responses in rice. Microbiol. Res. 154:1-5.

Wäspi, U., Schweizer, P., and Dudler, R. 2001. Syringolin reprograms wheat to undergo hypersensitive cell death in a compatible interaction with powdery mildew. Plant Cell 13:153-161.

$\mathrm{Xu}, \mathrm{G}$. W., and Gross, D. C. 1988. Physical and functional analyses of the syrA and $s y r B$ genes involved in syringomycin production by Pseudomonas syringae pv. syringae. J. Bacteriol. 170:5680-8.

Yasuta, T., Okazaki, S., Mitsui, H., Yuhashi, K. I., Ezura, H., and Minamisawa, K. 2001. DNA sequence and mutational analysis of rhizobitoxine biosynthesis genes in Bradyrhizobium elkanii. Appl. Environ. Microbiol. 67:4999-5009. 